\title{
LAS HUELLAS DEL AFECTO
}

\author{
Delfina Miller ${ }^{1}$
}

Reseña* a cargo de del Prof.Emérito Dr.Ricardo Bernardi Doctor en Psicología por la Universidad de Buenos Aires, Argentina Master en Psicoanálisis. IPU, Uruguay Master en Salud Mental, Universidad Católica de Pelotas, Brasil. Doctor en Medicina, especialidad en Psiquiatría, Universidad de la República, Uruguay

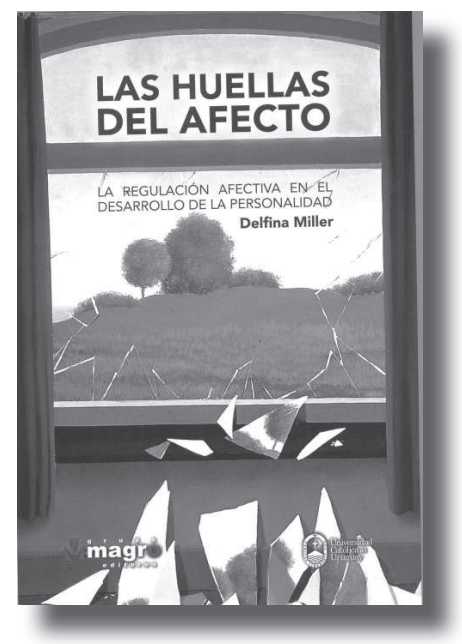

En Las Huellas del Afecto, Delfina Miller ha logrado combinar dos cualidades que son muy difíciles de reunir: por un lado constituye una investigación de alto valor académico, que apunta a desarrollar conocimientos de valor general y, por otro, de un modo muy concreto, nos permite aproximarnos y comprender mejor problemas de nuestro país que nos preocupan colectivamente, como es el caso de la integración social y las conductas violentas o disfuncionales.

Nacido de una tesis de doctorado en la Universidad de Buenos Aires, el libro explora el papel de la regulación afectiva en el desarrollo de la personalidad, apoyándose en el estudio de niños de entre 5 y 8 años procedentes de diversos medios socioeconómicos de Montevideo. Uno de los aspectos estudiados, que muestra la relación entre la disregulación afectiva y la depresión en la infancia, constituye una de las investigaciones premiadas recientemente por la Asociación Psicoanalítica Internacional (Congreso de Praga, 2013).

En su reflexión, Delfina Miller logra conjuntar la investigación empírica sistemática tanto con el análisis conceptual riguroso que surge de una revisión exhaustiva de la literatura como con la comprensión profunda de las situaciones individuales nacida de la experiencia clínica. Para ello se hizo uso de distintos instrumentos de evaluación del niño, incluidas pruebas de conductancia dérmica, y en especial del FIRE, que es un procedimiento de valoración del juego naturalístico, a partir de una guía elaborada por la autora. A través de dicho instrumento, el niño pone de manifiesto su modo de hacer frente a situaciones estresantes imprevistas, de acuerdo a la forma en la que los afectos son procesados en su mundo interior y en su relación con los demás. Los datos de este estudio son analizados tanto en forma cuantitativa como cualitativa.

A través de esta investigación, el concepto de regulación afectiva se convierte en una llave que le permite a la autora mostrar la forma en la que el niño, en contacto con su entorno, ha logrado construir su subjetividad y lo que esto nos dice de su pasado y sobre las consecuencias que esto puede tener para su vida futura y su convivencia social. La primera parte del libro nos permite acceder a un examen minucioso, profundo y crítico de los trabajos publicados sobre estos temas, lo que hace su aporte valioso a diversas disciplinas. Al terminar de leer el libro queda en nuestras

\footnotetext{
* En esta reseña se transcribe el Prólogo realizado por el Prof. Emérito Dr. Ricado Bernardi, bajo el permiso del Grupo Magro.
} 
manos un conjunto de conclusiones muy bien fundamentadas, que a su vez obliga a reflexionar sobre cuáles son las intervenciones psicosociales más útiles para nuestro medio.

Decir qué es un afecto parece ser lo más sencillo del mundo, pues el término mismo puede definirse en forma ostensiva haciendo referencia a la experiencia directa. Pero la cuestión se complejiza cuando vemos que la vida afectiva constituye un amplio abanico, que por un lado hunde sus raíces en nuestras experiencias emocionales corporales, y por el otro lado se desgrana en sentimientos más finos que son parte constitutiva de nuestro mundo interno y de nuestra vida de relación. Los afectos nos guían y dan sentido a la vida, pero también nos desbordan y nos llevan a situaciones en las que ya dejamos de reconocernos a nosotros mismos. Como señala Delfina Miller, los afectos son reguladores, pero también necesitan ser regulados; son parte de nuestra identidad, pero necesitan ser integrados de una forma que otorguen cohesión a nuestro sentido de la existencia. Esta modulación de nuestras emociones y sentimientos se consolida, como muestra el texto, a partir de la interacción con los padres y cuidadores a partir de los primeros momentos de la vida. Para comprender nuestros afectos necesitamos que nos sean reflejados por otros, cuyas reacciones nos permiten comprender nuestras propias reacciones y el significado emocional de las situaciones que estamos viviendo.

Frente a la preocupación por los fenómenos de violencia social y la necesidad de crear espacios en nuestra sociedad en los que la mediación y la cooperación mutua sean posibles, este libro constituye un material de reflexión imprescindible. Por esta razón, constituye un texto imprescindible para los profesionales que buscan actualizar su conocimiento sobre el desarrollo afectivo del niño y sus relaciones con los procesos cognitivos y sociales. Tiene también indudable valor para todo lector interesado en estos temas, pues aporta elementos de reflexión sobre problemas actuales que, precisamente por su complejidad necesitan respuestas que estén apoyadas en estudios científicos.

Miller, D. (2013). Las huellas del afecto. Montevideo: Magro.

1(N. de la Ed.) La Prof. Delfina Miller es Doctora en Psicología por la Universidad de Buenos Aires; Master en Psicología Clínica del Niño y del Adolescente por la Universidad Católica del Uruguay; Postgrado de Especialización en Psicoterapia Psicoanalítica por AUDEPP, Uruguay. Coordinadora de la Maestría en Psicología Clínica del Niño y del Adolescente, Universidad Católica del Uruguay. Con muy reconocida trayectoria profesional y académica, ha recibido varios premios en la materia, entre ellos el Premio a la Investigacion en Depresión de la Internacional Psychoanalytic Association (2013). 